Revue Revue de l'histoire des religions

del'histoire des religions

4 | 2021

La magie entre Antiquité et Moyen Âge : traditions, innovations, autorités

La Prakaranapañcikā de Śālikanātha. Chapitre 6, section 1. Le moyen de connaissance valide et la perception. Traité Mìmāmsaka d'épistémologie, présenté, traduit et commenté par Jean-Marie VERPOORTEN

Louvain-la-Neuve, Éditions Peeters (« Publications de l'Institut orientaliste de Louvain », 70), 2018

Guillaume Ducœur

\title{
OpenEdition
}

Journals

Édition électronique

URL : https://journals.openedition.org/rhr/11537

DOI : $10.4000 /$ rhr. 11537

ISSN : 2105-2573

Éditeur

Armand Colin

Édition imprimée

Date de publication : 1 décembre 2021

Pagination : 741-743

ISBN : 978-2-200-93378-4

ISSN : 0035-1423

Référence électronique

Guillaume Ducœur, «La Prakaraṇapañcikā de Śälikanātha. Chapitre 6, section 1. Le moyen de connaissance valide et la perception. Traité Mìmāmsaka d'épistémologie, présenté, traduit et commenté par Jean-Marie Verpoorten », Revue de l'histoire des religions [En ligne], 4 | 2021, mis en ligne le 01 décembre 2021, consulté le 06 janvier 2022. URL : http://journals.openedition.org/rhr/11537 ; DOI : https://doi.org/10.4000/rhr.11537

Ce document a été généré automatiquement le 6 janvier 2022

Tous droits réservés 


\section{La Prakaraṇapañcikā de Sālikanātha. Chapitre 6, section 1. Le moyen de connaissance valide et la perception. Traité Mìmāmsaka d'épistémologie, présenté, traduit et commenté par Jean-Marie VERPOORTEN}

Louvain-la-Neuve, Éditions Peeters (« Publications de l'Institut orientaliste de Louvain », 70), 2018

Guillaume Ducœur

\section{RÉFÉRENCE}

La Prakaraṇapañcikā de Śălikanātha. Chapitre 6, section 1. Le moyen de connaissance valide et la perception. Traité Mìmāmsaka d'épistémologie, présenté, traduit et commenté par JeanMarie VERPOORTEN, Louvain-la-Neuve, Éditions Peeters ( Publications de l'Institut orientaliste de Louvain », 70), 2018, 27 cm, XXII + 215 p., 89 €, ISBN 978-90-429-3497-9.

1 Les débats portant sur la réalité des perceptions au fondement de toute connaissance ont animé les écoles de pensée indiennes tant brāhmaniques que śramaniques durant des siècles et nombreux furent les théoriciens qui reprirent, commentèrent, confirmèrent ou rejetèrent les spéculations de leurs devanciers tout comme les exemples qu'ils énoncèrent. En ceci, les penseurs indiens s'interrogèrent à l'égal des philosophes grecs et si Carnéade (II ${ }^{\mathrm{e}} \mathrm{s}$. av. J.-C.) affirmait, selon Sextus Empiricus (II ${ }^{\mathrm{e}} \mathrm{s}$. apr. J.-C.), dans ses Hypotyposes pyrrhoniennes (1.33), qu'au premier coup d'œil, une

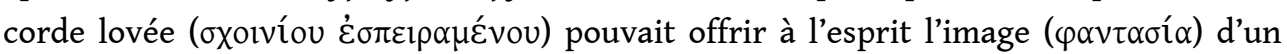
serpent ( $\dot{\omega} \varsigma$ ámò ó $\varphi \varepsilon \omega \varsigma$ ) et qu'un examen attentif pouvait dissiper cette méprise, le 
maître bouddhiste Dignāga ( $\mathrm{V}^{\mathrm{e}}-\mathrm{VI}^{\mathrm{e}} \mathrm{s}$. apr. J.-C.) enseignait dans son Hastavālaprakaraṇavrtti qu'après avoir observé la corde (rajjum dṛșțā) que l'esprit avait prise, au premier abord, pour un serpent (sarpamanaskāro), il convenait d'en déduire que cette perception première était dénuée de toute réalité (nirarthakah). Dès lors se posait à tous la question de savoir ce qui relevait précisément de la perception des objets des organes des sens et de définir des moyens sûrs permettant d'appréhender le monde phénoménal, car pour celui qui prend une corde pour un serpent, seul le serpent est, sur l'instant, réalité - la corde n'ayant aucune existence propre pour lui. Aussi, dans la théorie de la connaissance de l'école brāhmanique mīmāṃsā, qui fut enseignée par la branche fondée par Prabhākara ( $\mathrm{vI}^{\mathrm{e}} \mathrm{s}$. apr. J.-C.), sont énumérés cinq moyens de connaissance valide (pramāṇa), à savoir la perception (pratyakṣa), l'inférence (anumāna), la parole (śabda), l'identification analogique (upamāna) et la présomption (arthāpatti).

2 Dans le présent ouvrage, Jean-Marie Verpoorten (dorénavant JMV), éminent spécialiste de la mīmāmsāâ, a savamment traduit et commenté la section de la Prakaraṇapañ cikā de Śālikanātha ( $\mathrm{VIII}^{\mathrm{e}}-\mathrm{IX}^{\mathrm{e}} \mathrm{s}$. apr.J.-C.) relative à la définition générale du moyen de connaissance valide ou pramāṇa ainsi qu'au premier d'entre les cinq, à savoir la perception ou pratyakșa. Commencé dans les années 1980 (voir l'Avant-propos), ce travail est le fruit de plus de trente ans de recherche sur les traités mīmāṃsaka et offre à la communauté scientifique un magnifique aperçu des discussions, voire des polémiques, entre l'école prābhākara et, notamment, celles du nyāya et du yogācāra autour de ces délicates questions d'interprétation épistémologique. Plus encore, le travail lexicographique de JMV est une précieuse avancée dans le domaine de la traduction en langue française d'une terminologie sanskrite souvent difficile à saisir.

3 Le volume est divisé en deux parties d'inégale longueur, une introduction (p. 1-26), précédée d'une bibliographie (p.ix-xxii), et le texte sanskrit accompagné d'une traduction annotée (p. 27-197), suivi des index des textes sanskrits cités (p. 199-202) et des termes sanskrits (p. 203-207). Dans son introduction, JMV recontextualise la Prakaraṇapañcikā et expose les incertitudes sur la paternité du texte ici traduit - la première section (pariccheda) du sixième chapitre (prakarana) intitulé «Examen approfondi des moyens de connaissance valide» (pramāṇapārāyaṇa)-, et, plus largement, du sixième chapitre en son entier. Il montre qu'une histoire rédactionnelle de ce traité, attribué à Śālikanātha, reste encore à faire pour pouvoir en déterminer le ou les auteurs. S'ensuit la présentation concise des différents arguments avancés (p. 9-26) qui permettra au lecteur d'entrer dans la méthode doxographique (siddhānta) de l'auteur indien et d'apprécier les sources citées et discutées par ce dernier, provenant soit des milieux mīmāmsaka eux-mêmes, notamment le fondateur Jaimini (IV ${ }^{\mathrm{e}}-\mathrm{III}{ }^{\mathrm{e}}$ s. av. J.-C.), son maître Prabhākara et son rival Kumārila (VII ${ }^{\mathrm{e}}-\mathrm{VIII}{ }^{\mathrm{e}}$ s. apr. J.-C.), soit d'écoles autres telles celles bouddhiques des yogācārin (Dharmakīrti, VII ${ }^{\mathrm{e}}$ s. apr. J.C.), des sautrāntika et des vijñānavādin, ou celles āstika des vaiśeșika et des naiyāyika.

4 La partie "Texte et traduction annotée » est la pièce maîtresse de l'ouvrage et est divisée elle-même en deux parties, l'une concernant le moyen de connaissance valide (p.31-72), l'autre la perception (p.73-197), cette dernière plus volumineuse et comptant 615 lignes sanskrites, l'ensemble du texte en transcription latine reproduisant celui édité en devanāgarī par Subrahmanya Sastri en 1961. JMV a, par ailleurs, opéré une segmentation du texte en 122 portions (T1-T122) afin d'en dégager une structure argumentaire et d'en faciliter ainsi sa lecture et sa compréhension. 
Dans la première partie relative à la définition du pramāṇa, Śălikanātha réfute en premier lieu la définition qu'en avait donnée Dharmakīrti, dans son Pramānavāarttika, et qui incluait, dans le champ possible de la connaissance valide, le souvenir (smṛti). Puis, il rejette la définition professée par les disciples de son adversaire Kumārila au sujet d'une possible connaissance incertaine ou erronée et réitère alors la définition de son maître Prabhākara en perpétuant les exemples de la concrétion nacrée prise pour une pépite d'argent, la couleur blanche d'une conque perçue jaune par une personne atteinte d'hyperbilirubinémie ou bien encore le phénomène de double lune.

Dans la seconde partie, Śâlikanātha débat sur la connaissance perceptive et ouvre la section qu'il lui consacre par l'évaluation de la définition du pratyakșa telle qu'elle était énoncée dans l'école du nyāya et plus précisément dans les Nyāyasūtra attribués à Gautama. Le mīmāmsaka opte alors pour faire entrer dans un dialogue contradictoire les tenants du nyāya, du vaiśeșika et du bouddhisme, voire rapporte les thèses bouddhiques sur la perception qui opposaient l'école des sautrāntika à celle des vijñānavādin, utilisant ainsi un procédé dialectique faisant l'économie d'un nouveau développement réfutatoire. Les questions touchant à la connaissance perceptive des objets des organes des sens - notons un passage important sur la théorie de la faculté visuelle avancée par les naiyāyika mais contredite par les bouddhistes-, à la connaissance réflexive, à la fonction du sens interne (manas) dans le processus cognitif, au rôle joué par le souvenir pouvant fausser la perception d'un objet, etc. sont autant d'éléments exposés et discutés tout au long de cette section par śálikanātha et analysés et expliqués au fur et à mesure de leur lecture par JMV avec précision et perspicacité.

7 Au-delà de la position doctrinale et épistémologique personnelle de Śālikanātha qui perpétua l'enseignement de son maître Prabhākara et défendit les spécificités de son école mīmāmsaka, le texte proposé par JMV donne à voir l'état des débats métaphysiques et des traditions commentariales au tournant du IX $\mathrm{e}$. apr. J.-C. dans les milieux intellectuels des grands courants de pensée indiens qui intéresse tout autant l'indianisme que l'histoire comparée des religions.

\section{AUTEURS}

\section{GUILLAUME DUCEEUR}

Université de Strasbourg. 